\title{
Analysis of Gas Nitriding Characteristics under Different Cold Hardening and Nitriding Pressure Conditions for Low-Carbon Low-Alloy Steel
}

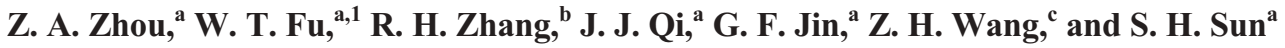 \\ a State Key Laboratory of Metastable Materials Science and Technology, College of Materials \\ Science and Engineering, Yanshan University, Qinhuangdao, China \\ ${ }^{b}$ Hebei Province Key Laboratory of Modern Metallurgy, College of Metallurgy and Energy, North \\ China University of Science and Technology, Tangshan, China \\ c College of Mechanical Engineering, Yanshan University, Qinhuangdao, China \\ 1.wtfu@ysu.edu.cn; zzasdtc@126.com
}

A new approach to quick preparation of a nitrided case for low-carbon low-alloy steels was proposed. It is based on cold hardening and pressurized gas nitriding. The microstructure, surface hardness, thickness, and corrosion resistance of the nitrided layer on low-carbon low-alloy steel (20CrMnTi) were investigated after the nitriding at $510^{\circ} \mathrm{C}$ for $5 \mathrm{~h}$ under different cold rolling reduction (0-60\% CR) and nitriding pressure (1-5 atm). The results show that this technique can significantly improve the nitriding steel efficiency with the nitrided layer mainly composed of $\mathrm{Fe}_{2-3} \mathrm{~N}$ and $\mathrm{Fe}_{4} \mathrm{~N}$ nitrides. At constant nitriding pressure, the nitrided layer hardness first increases and then decreases with the amount of cold hardening. At the constant hardening, the nitrided layer hardness and corrosion resistance increase with the nitriding pressure. For the sample nitrided at $510^{\circ} \mathrm{C}$ for $5 \mathrm{~h}$ under $30 \% \mathrm{CR}$ and a pressure of $5 \mathrm{~atm}$, the nitrided layer exhibits optimal properties: hardness of $825 \mathrm{HV}$ and thickness of $310 \mu \mathrm{m}$.

Keywords: low-carbon low-alloy steel, nitride, nitriding pressure, cold hardening, nitriding efficiency.

Introduction. 20CrMnTi steel is a typical low-carbon low-alloy steel that exhibit high strength, toughness, and fatigue performance after being carburized. It is widely used to manufacture gears, shafts, and piston parts. However, deformation and cracking occur easily at high temperatures $\left(900-950^{\circ} \mathrm{C}\right)$ required for carburization, which severely limits the application in the steel parts required to be large and accurate [1-4]. In contrast, the commonly used gas nitriding $(\mathrm{GN})$ at $500-580^{\circ} \mathrm{C}$ can greatly improve the workpiece surface and fatigue strength, corrosion resistance, as well as reduce the workpiece deformation during its processing. However, to obtain a thicker nitrided layer (NL), conventional GN (CGN) requires a longer process cycle $(20-80 \mathrm{~h})$, whith higher energy and equipment depreciation losses [5-9]. Thus, a new GN process is required for industrial applications that are more rapid, energy-efficient and reliable than existing methods.

Many reports focused on rapid GN processes:. Kundalkar et al. [10] achieved good fatigue performance of H13 steel through a rapid two-stage GN process, but the NL thickness was only $145 \mu \mathrm{m}$. Tong et al. [11-13] reported that the nitriding efficiencies of pure $\mathrm{Fe}$ and $38 \mathrm{CrMoAl}$ steel were improved through surface shot peening, and that the nitriding temperatures were reduced appreciably. However, its nitriding process took place under atmospheric pressure, and the effect of pressure on nitriding efficiency was not considered. We have proposed a series of pressurized GN methods [14-16] that involve increasing the nitriding pressure. This increases the physical adsorption of nitrogen atoms at the workpiece surface and the interface reaction rate, thereby accelerates the nitriding dynamics process. However, the effect of cold hardening and nitriding pressure on GN characteristics of low-carbon low-alloy steel has not been clarified yet. 
In this study, the microstructure, surface hardness, thickness, and corrosion resistance for $20 \mathrm{CrMnTi}$ steel were investigated to substantiate the development of new rapid nitriding technology that may replace the carburization.

1. Experimental. The normalized $20 \mathrm{CrMnTi}$ commercial steel plate was adopted as the test material, with the following chemical composition (wt.\%): $0.21 \mathrm{C}, 0.98 \mathrm{Mn}, 1.13 \mathrm{Cr}$, $0.26 \mathrm{Si}, 0.05 \mathrm{Ti}, 0.028 \mathrm{P}, 0.015 \mathrm{~S}$, and balance Fe. Samples of the tested steel were cut into $6 \mathrm{~mm}$ and cold-rolled (CR) $10-60 \%$ in the thickness direction. The nitriding was carried out using a specially designed furnace [17]. All samples were nitrided at $510^{\circ} \mathrm{C}$ for $5 \mathrm{~h}$ using flowing $\mathrm{NH}_{3}(99.99$ vol.\%) under gas pressures range of 1-5 atm, after which they were left in the furnace to cool to $100^{\circ} \mathrm{C}$. The cross-sectional microstructure of the nitrided samples was examined under an Axiovert 200 optical microscope (OM). Micro- structure features in the NLs were characterized with a JEM-2010 transmission electron microscope (TEM). Phase analysis of the NLs was done on a D/MAX-PC 2500 X-ray diffractometer with $\mathrm{CuK} \alpha$ radiation, operated at $40 \mathrm{~mA}$ and $40 \mathrm{kV}$. The depth- dependent hardness of the nitrided samples was measured using an FM-ARS 9000 Vickers micro- hardness tester with a load of $200 \mathrm{~g}$ and a time of $10 \mathrm{~s}$. The samples after nitriding were cut into $10 \times 5 \mathrm{~mm}$ and then removed the cutting marks by $1000 \#$ abrasive paper. Samples, which sections were covered by cold tesserae (acrylic acid) in hydrochloric acid solution were subjected to the static corrosion weight loss, with fixed time of their removal, and weighted after alcohol flushing and drying.

\section{Results and Discussion.}

2.1. Microstructure of Nitrided Layer. X-ray diffraction (XRD) patterns for the surface layers of samples that were nitrided at $510^{\circ} \mathrm{C}$ for $5 \mathrm{~h}$ under different experimental conditions $(0-60 \% \mathrm{CR}, 1-5 \mathrm{~atm})$ are shown in Fig. 1. Apparently, for the samples pre-deformed less than $30 \%$, either the $\mathrm{Fe}_{2-3} \mathrm{~N}$ or $\mathrm{Fe}_{4} \mathrm{~N}$ phase has not been found in the NL after CGN process, only the $\alpha-(\mathrm{Fe}, \mathrm{N})$ phase (i.e., rich-N ferrite) is formed. Pre-treating of the sample with $30-40 \%$ CR leads to a NL microstructure composed of $\alpha-(\mathrm{Fe}, \mathrm{N})$ phase and slight $\mathrm{Fe}_{4} \mathrm{~N}$ phase. When the deformation was over $40 \%$, only $\alpha$-(Fe, N) phase revealed (Fig. 1a). Thus, the nitrides' amount in NLs of 20CrMnTi steel after CGN firstly grew and then dropped with cold hardening deformation.

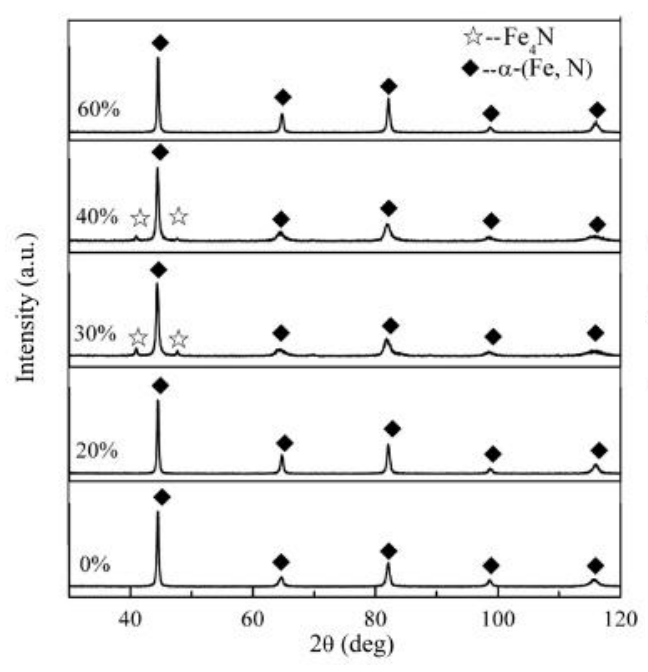

a

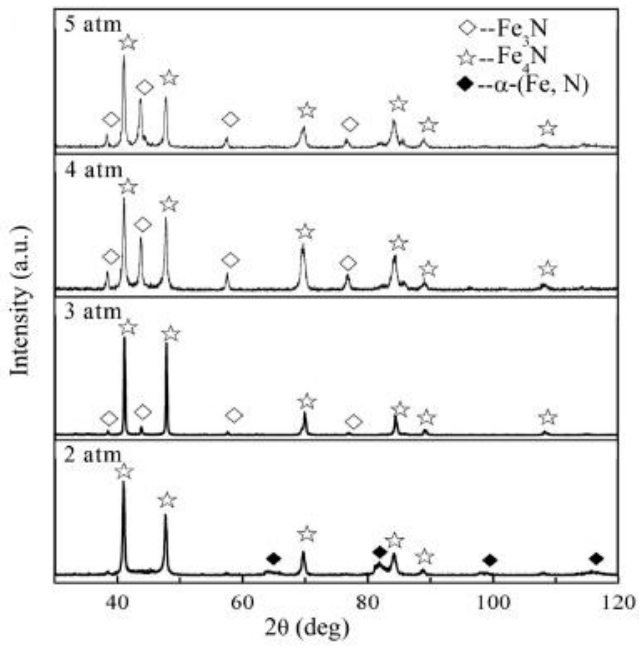

b

Fig. 1. XRD patterns for surface layers nitrided at $510^{\circ} \mathrm{C}$ for $5 \mathrm{~h}$ with different deformation and pressure values: (a) $0-60 \% \mathrm{CR}, 1 \mathrm{~atm}$; (b) $30 \% \mathrm{CR}, 2-5 \mathrm{~atm}$. 
The NL microstructure mainly consists of $\mathrm{Fe}_{2-3} \mathrm{~N}$ and $\mathrm{Fe}_{4} \mathrm{~N}$ phases (Fig. 1b) after $30 \%$ $\mathrm{CR}$ and nitriding under gas pressures of $1-5$ atm at $510^{\circ} \mathrm{C}$ for $5 \mathrm{~h}$. With increasing nitriding pressure, the density of the gas inside the furnace and the probability of collision between atoms increase. The probability of nitrogen atoms accessing the specimen surface also grows, as does the $\mathrm{Fe}_{2-3} \mathrm{~N}$ phase number. On the other hand, because the decomposition of $\mathrm{NH}_{3}$ in the furnace during nitriding is a reversible reaction suppressed with increasing pressure, while the partial pressure of $\mathrm{NH}_{3}$ can increase the activity coefficient of $\mathrm{N}$ atoms, thus the reaction rate of $\mathrm{NH}_{3}$ was accelerated.

Cross-sectional $\mathrm{OM}$ images of the samples treated at $510^{\circ} \mathrm{C}$ for $5 \mathrm{~h}$ under different deformation and pressure values are shown in Fig. 2. When deformation increased from 0 to $30 \%$, a compound layer appeared. and the NL thickness increased from 50 to $85 \mu \mathrm{m}$ (Fig. 2a and b). Thus, the cold hardening pre-deformation promoted the CGN efficiency [12]. When the nitriding pressure was raised from 2 to $5 \mathrm{~atm}$, the thicknesses of compound layer and NLs increased from 20 and $75 \mu \mathrm{m}$ to 160 and $310 \mu \mathrm{m}$ (Fig. 2c and d), respectively. This implies that the pressure increase not only accelerated the nitriding rate effectively but also thickened the compound and diffusion layers at the same nitriding temperature and nitriding period.
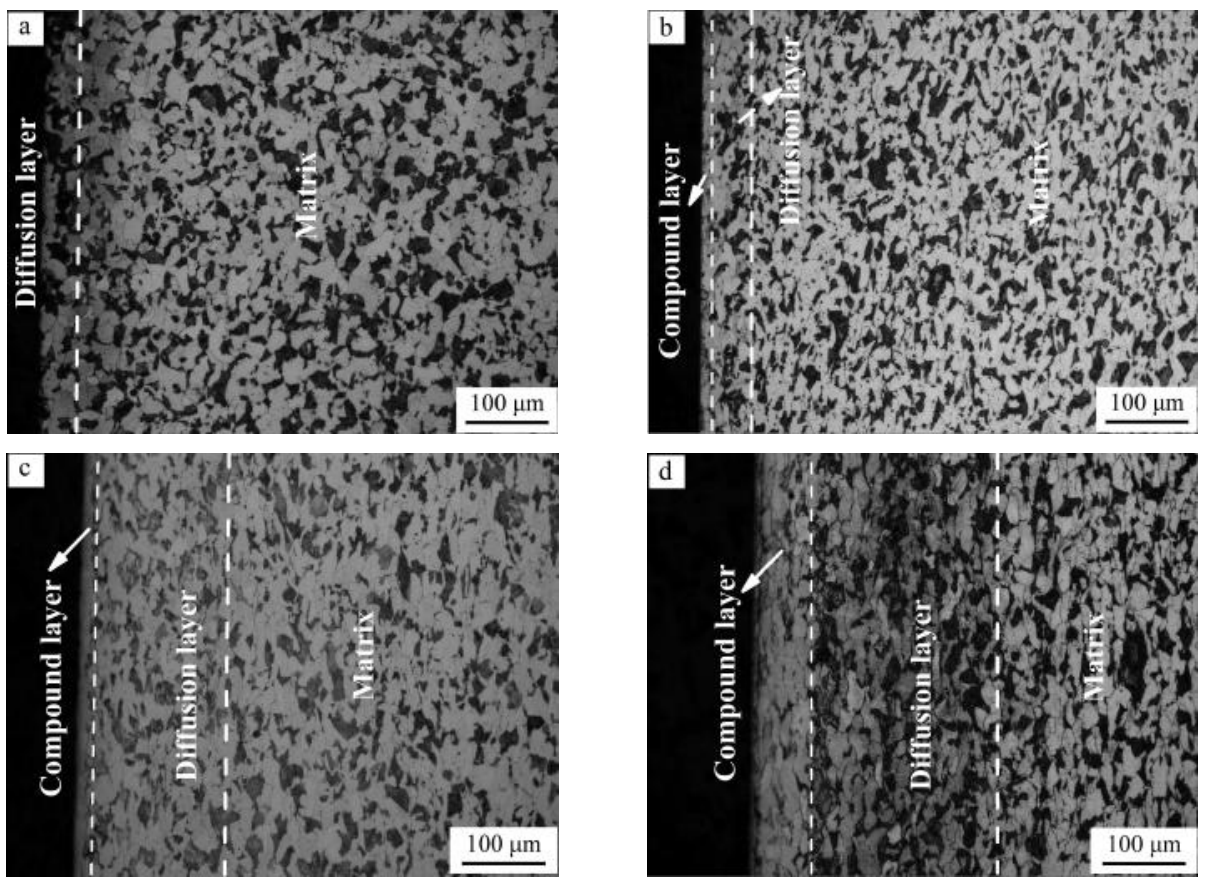

Fig. 2. Cross-sectional OM images of samples treated at deformation and pressure values: (a) $0 \%$ CR, 1 atm; (b) 30\% CR, 1 atm; (c) 30\% CR, 2 atm; (d) 30\% CR, 5 atm.

A typical TEM image of a sample treated at $510^{\circ} \mathrm{C}$ for $5 \mathrm{~h}$ under $30 \% \mathrm{CR}$ and nitriding pressure of $4 \mathrm{~atm}$ is shown in Fig. 3. It is very evident that a large number of dislocations were distributed in the NL of the deformed sample (Fig. 3). When the media pressure reaches $4 \mathrm{~atm}$ the precipitates were observed in the NLs, and the precipitate identified by SAED pattern was the $\mathrm{Fe}_{4} \mathrm{~N}$ phase (Fig. 3b).

2.2. Hardness and Thickness of Nitrided Layer. Figure 4 shows the cross-sectional microhardness of $20 \mathrm{CrMnTi}$ steel treated under different conditions. For the CGN sample pre-treated after 10-60\% CR, the cross-sectional hardness first grew and then dropped with pre-treatment deformation, reaching its maximum value of $\sim 440 \mathrm{HV}$ at $30 \% \mathrm{CR}$ (Fig. 4a). 

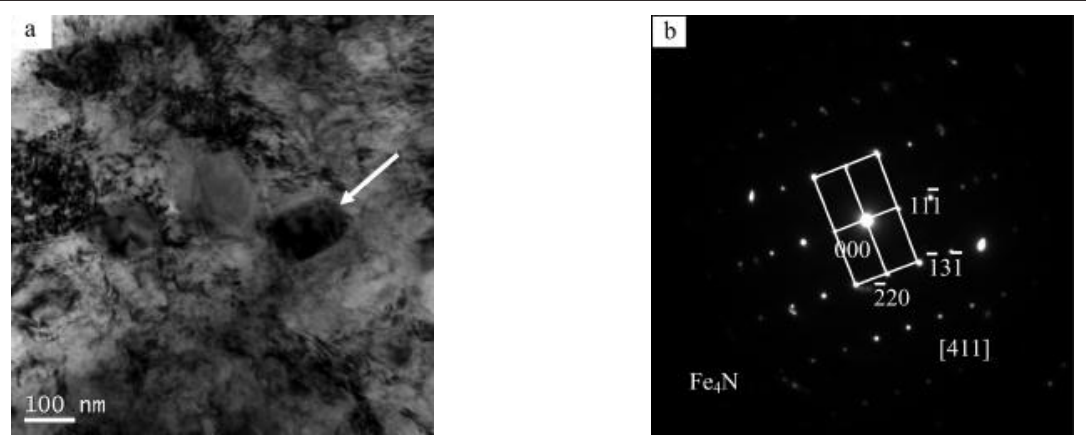

Fig. 3. Typical TEM bright-field image (a) and corresponding SAED pattern (b) for the sample treated at $510^{\circ} \mathrm{C}$ for $5 \mathrm{~h}$ under $30 \% \mathrm{CR}$ and a nitriding pressure of $4 \mathrm{~atm}$.

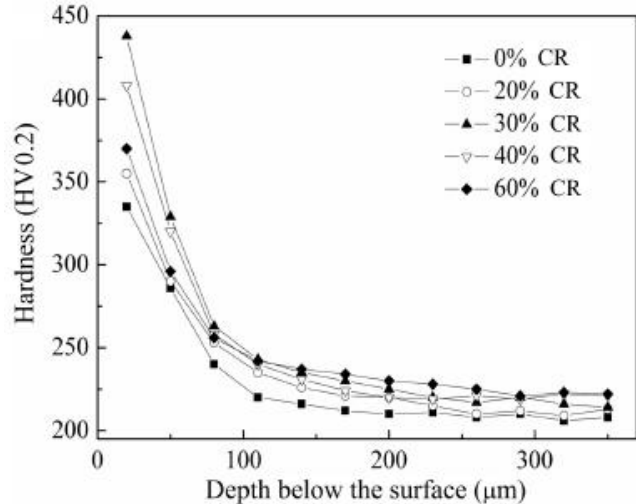

a

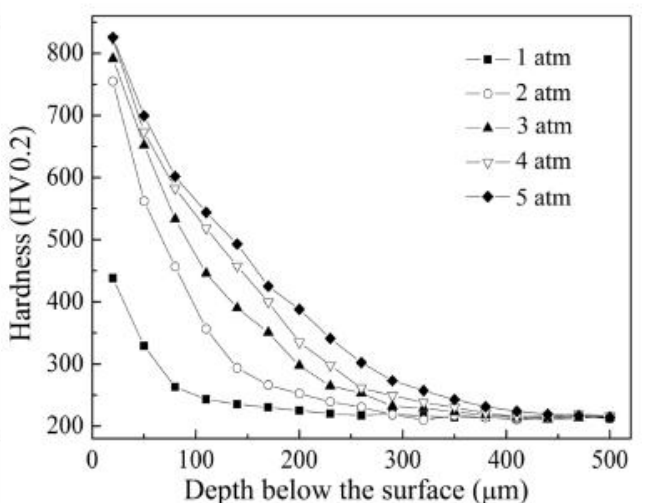

b

Fig. 4. Cross-sectional microhardness distribution curves of $20 \mathrm{CrMnTi}$ steel treated at $510^{\circ} \mathrm{C}$ for $5 \mathrm{~h}$ under different conditions: (a) 0-60\% CR, 1 atm; (b) $30 \% \mathrm{CR}, 1-5 \mathrm{~atm}$.

As soon as $\mathrm{Fe}_{4} \mathrm{~N}$ phase with higher toughness and hardness was formed, the surface hardness of the sample with $30-40 \%$ CR increased significantly. In particular, after nitriding, samples possessed the matrix hardness almost as high as that after pre-treatment.

Figure $4 \mathrm{~b}$ shows the cross-sectional microhardness distribution curves of $20 \mathrm{CrMnTi}$ steel treated at $510^{\circ} \mathrm{C}$ for $5 \mathrm{~h}$ under $30 \% \mathrm{CR}$ and nitriding pressure of $1-5 \mathrm{~atm}$. For the PGN sample pre-treated after $30 \% \mathrm{CR}$ the microhardness increases with increasing nitriding pressure, albeit with less sharply. Thus, higher nitriding pressures result in higher gas density in the nitriding furnace, better surface adsorption of $\mathrm{NH}_{3}$ molecules, and faster interface reactions, which implies that PGN efficiency was improved significantly.

The evolution of measured average thickness values of NLs in 20CrMnTi steel treated at $510^{\circ} \mathrm{C}$ for $5 \mathrm{~h}$ under different conditions is depicted in Fig. 5. The NL thickness firstly grew and then dropped with deformation, while the maximum $(85 \mu \mathrm{m})$ depth of the nitride layer corresponded to the deformation value of $30 \%$. It is noteworthy that when the amount of cold hardening increased to 50 or $60 \%$, the surface hardness of the nitrided sample dropped. This is due to the closure of previously opened diffusion channels of nitrogen atoms: an increasse in the cold hardening deformation triggered a large number of dislocations to tangle. It can be seen that the effective hardening layer thickness increases with pressure, so that the hardened-layer thickness at $5 \mathrm{~atm}$ is $265 \%$ of that at $1 \mathrm{~atm}$.

2.3. Corrosion Resistance. The weight losses of $20 \mathrm{CrMnTi}$ steel treated at $510^{\circ} \mathrm{C}$ for $5 \mathrm{~h}$ under different nitriding pressure in $10 \%$ hydrochloric acid are shown in Fig. 6. The rate of weight loss per unit area of sample dropped significantly after nitriding. The curve 


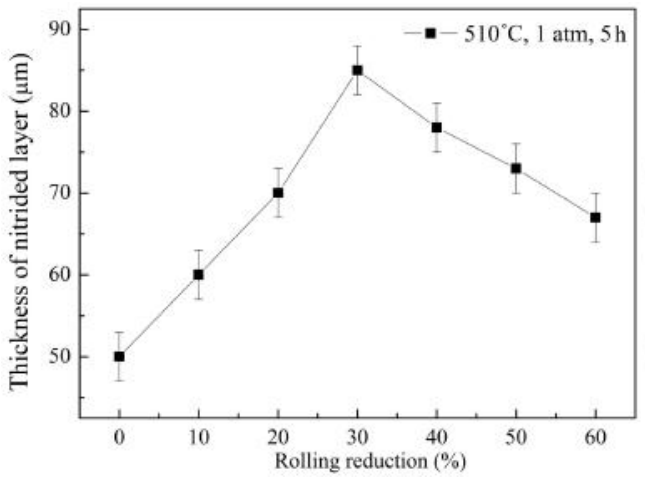

a

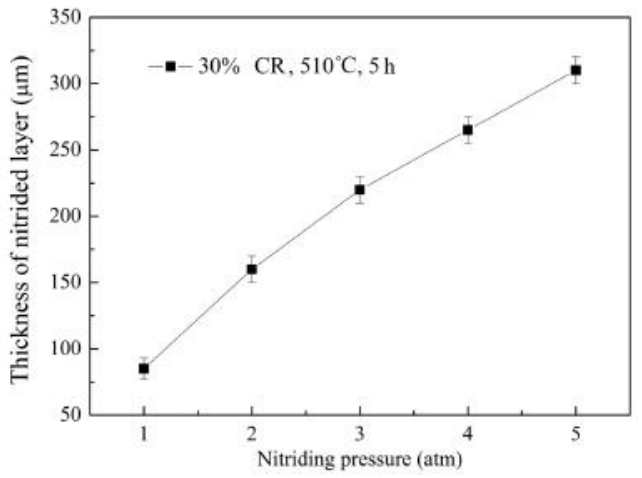

$\mathrm{b}$

Fig. 5. Measured average thickness of NL of 20CrMnTi steel treated under different conditions: (a) 0-60\% CR, $1 \mathrm{~atm}$; (b) 30\% CR, 1-5 atm. (The error bars of the measurements are indicated in the plots.)

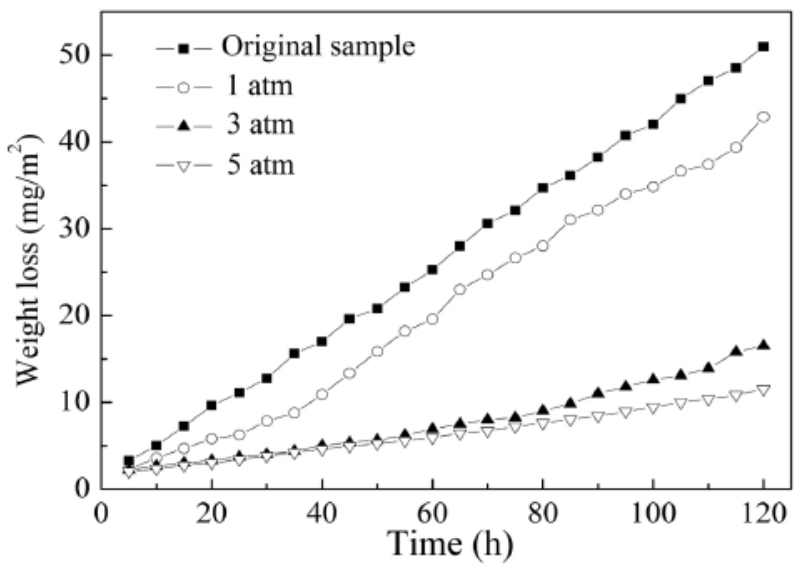

Fig. 6. Corrosion weight loss against corrosion time for differently treated 20CrMnTi steel samples placed into $10 \%$ hydrochloric acid.
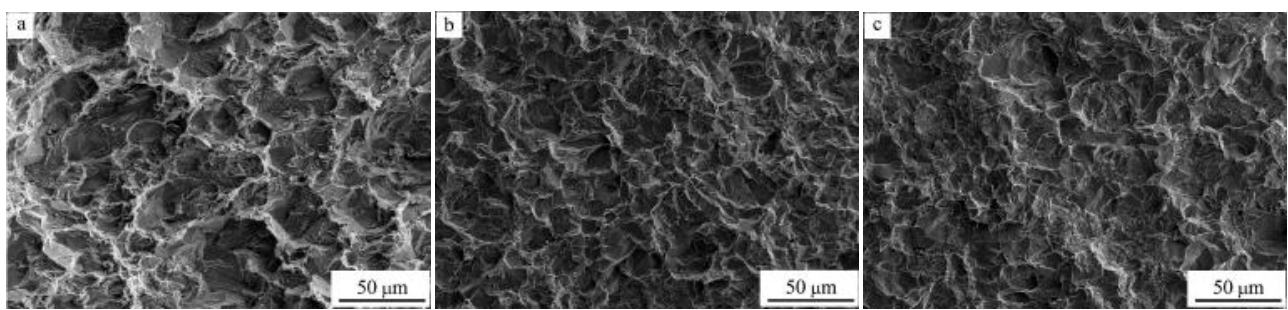

Fig. 7. Corrosion morphology of differently treated 20CrMnTi steel: (a) original sample; (b) 1 atm; (c) $3 \mathrm{~atm}$.

for CGN (1 atm) is close to that of the original sample with increased corrosion time, as NL is too thin to influence the corrosion resistance. Combined with the XRD results, the surface layer was identified as $\alpha-(\mathrm{Fe}, \mathrm{N})$ phase, which has a feeble contribution to the corrosion resistance improvement. However, the appearance of $\mathrm{Fe}_{2-3} \mathrm{~N}$ and $\mathrm{Fe}_{4} \mathrm{~N}$ phases at pressures of 3 and $5 \mathrm{~atm}$, respectively, which improve the corrosion resistance [18, 19], led to an appreciable drop in the corrosion weight loss. 
The corrosion morphologies of differently treated 20CrMnTi steel placed in $10 \%$ hydrochloric acid for $120 \mathrm{~h}$ are shown in Fig. 7. The surface of the original sample without nitriding treatment was left with very deep and intensive corrosion pits, whereas there was evidently considerably less damage to the nitrided samples.

\section{Conclusions}

1. As compared with CGN, the combined cold hardening and PGN improved the nitriding efficiency of the low-carbon low-alloy steel. The NL thickness formed under pressure of $5 \mathrm{~atm}$ amounted to $265 \%$ of that formed under $1 \mathrm{~atm}$.

2. The NL mainly contained $\mathrm{Fe}_{2-3} \mathrm{~N}$ and $\mathrm{Fe}_{4} \mathrm{~N}$ nitrides. At the constant nitriding pressure, the NL hardness firstly grew and then dropped with cold hardening deformation. For constant deformation, the NL hardness increased with the nitriding pressure.

3. With an increase in the nitriding pressure, the corrosion resistance of NL was gradually improved.

4. The NL of the sample under $30 \% \mathrm{CR}$ and nitriding pressure of $5 \mathrm{~atm}$ exhibited the optimal properties, namely: the hardness of $825 \mathrm{HV}$ and thickness of $310 \mu \mathrm{m}$.

Acknowledgments. This work was supported by the National Natural Science Foundation of China (Grant No. 51505416), the Foundation for Young Scholars in Yanshan University (Grant No. 14LGA004) and the Post-Doctoral Research Project of Hebei Province (Grant No. B2016003029).

1. C. Stickels, "Gas carburizing of steels," in: ASM Handbook Volume 4: Heat Treating, ASM International (1991), pp. 312-324.

2. Y. Lv, L. Lei, and L. Sun, "Effect of shot peening on the fatigue resistance of laser surface melted 20CrMnTi steel gear," Mater. Sci. Eng. A, 629, 8-15 (2015).

3. B. Selcuk, R. Ipek, M. B. Karamis, and V. Kuzucu, "An investigation on surface properties of treated low carbon and alloyed steels (boriding and carburizing)," $J$. Mater. Process. Tech., 103, No. 2, 310-317 (2000).

4. A. V. D. Santos, C. A. S. Perez, D. Muenchen, and T. P. Anibele, "First principles calculations of the magnetic and hyperfine properties of $\mathrm{Fe} / \mathrm{N} / \mathrm{Fe}$ and $\mathrm{Fe} / \mathrm{O} / \mathrm{Fe}$ multilayers in the ground state of cohesive energy," Solid State Commun., 201, 120-124 (2015).

5. T. Bell, Source Book on Nitriding, ASM International, Metals Park, OH (1977).

6. T. Christiansen and M. A. J. Somers, "Low temperature gaseous nitriding and carburising of stainless steel," Surf. Eng., 21, Nos. 5-6, 445-455 (2005).

7. B. S. Yilbas, C. Karatas, A. F. M. Arif, and B. J. Abdul Aleem, "Laser gas assisted nitriding of alumina surfaces," Surf. Eng., 25, No. 3, 235-240 (2009).

8. C. Zheng, Y. H. Liu, H. X. Wang, et al., "Research on the effect of gas nitriding treatment on the wear resistance of ball seat used in multistage fracturing," Mater. Design, 70, 45-52 (2015).

9. E. J. Mittemeijer, "Fundamentals of nitriding and nitrocarburizing," in: $A S M$ Handbook Volume 4A: Steel Heat Treating Fundamentals and Processes, ASM International (2013), pp. 619-646.

10. D. Kundalkar, M. Mavalankar, and A. Tewari, "Effect of gas nitriding on the thermal fatigue behavior of martensitic chromium hot-work tool steel," Mater. Sci. Eng. A, 651, 391-398 (2016).

11. W. P. Tong, N. R. Tao, Z. B. Wang, et al., "Nitriding iron at lower temperatures," Science, 299, No. 5607, 686-688 (2003). 
12. W. P. Tong, Z. Hao, L. M. Wang, et al., "Low-temperature nitriding of $38 \mathrm{CrMoAl}$ steel with a nanostructured surface layer induced by surface mechanical attrition treatment," Surf. Coat. Tech., 202, No. 20, 4957-4963 (2008).

13. W. P. Tong, N. R. Tao, Z. B. Wang, et al., "The formation of $\varepsilon-\mathrm{Fe}_{3-2} \mathrm{~N}$ phase in a nanocrystalline Fe," Scripta Mater., 50, No. 5, 647-650 (2004).

14. B. Wang, W. T. Fu, F. Dong, et al., "Significant acceleration of nitriding kinetics in pure iron by pressurized gas treatment," Mater. Design, 85, 91-96 (2015).

15. B. Wang, S. H. Sun, M. W. Guo, et al., "Study on pressurized gas nitriding characteristics for steel 38CrMoAlA," Surf. Coat. Tech., 279, 60-64 (2015).

16. B. Wang, Z. Q. Lv, Z. A. Zhou, et al., "Combined effect of rapid nitriding and plastic deformation on the surface strength, toughness and wear resistance of steel 38CrMoAlA," IOP Conf. Ser. - Mat. Sci., 89, 299-308 (2015).

17. W. T. Fu, B. Wang, P. Zhao, et al., China Patent 201210530358.6 (2012).

18. A. Basu, J. D. Majumdar, J. Alphonsa, et al., "Corrosion resistance improvement of high carbon low alloy steel by plasma nitriding," Mater. Lett., 62, Nos. 17-18, 3117-3120 (2008).

19. R. L. O. Basso, R. J. Candal, C. A. Figueroa, et al., "Influence of microstructure on the corrosion behavior of nitrocarburized AISI H13 tool steel obtained by pulsed DC plasma," Surf. Coat. Tech., 203, Nos. 10-11, 1293-1297 (2009).

Received 15. 09. 2017 